\title{
Antibodies against the main immunogenic region of the acetylcholine receptor correlate with disease severity in myasthenia gravis
}

\author{
Tomoko Masuda, ${ }^{1}$ Masakatsu Motomura, ${ }^{1}$ Kimiaki Utsugisawa, ${ }^{2}$ Yuriko Nagane, ${ }^{2}$ \\ Ruka Nakata, ${ }^{1}$ Masahiro Tokuda, ${ }^{1}$ Taku Fukuda, ${ }^{1}$ Toshiro Yoshimura, ${ }^{3}$ \\ Mitsuhiro Tsujihata, ${ }^{4}$ Atsushi Kawakami ${ }^{1}$
}

'Department of Clinical Neuroscience and Neurology, Graduate School of Biomedical Sciences, Nagasaki University, Japan

2Department of Neurology, Hanamaki General Hospital, Japan

${ }^{3}$ Nagasaki University School of Health Science, Japan ${ }^{4}$ Department of Neurology, Nagasaki Kita Hospital, Japan

Correspondence to Dr M Motomura, Department of Clinical Neuroscience and Neurology, Graduate School of Biomedical Sciences, Nagasaki University, 1-7-1 Sakamoto, Nagasaki 852-8501, Japan; lems@net.nagasaki-u.ac.jp

TM and MM contributed equally to this work.

Received 22 March 2012 Revised 1 June 2012 Accepted 2 June 2012 Published Online First 4 July 2012

\section{ABSTRACT}

Objective We developed an assay that detects autoantibodies against the main immunogenic region (MIR) located at the extracellular end of the nicotinic acetylcholine receptor (AChR) $\alpha$ subunit, and investigated its clinical relevance in myasthenia gravis (MG).

Methods In this retrospective cohort study, we measured MIR antibody (Ab) titres in sera obtained before treatment and analysed their associations with clinical parameters in $102 \mathrm{MG}$ patients from two neurological centres. MIR Ab titres were determined using a modified competition immunoprecipitation assay in the presence or absence of monoclonal antibody 35.

Results 11 of 23 (47.8\%) ocular type and 66 of 72 (91.7\%) generalised type MG patients were positive for the presence of MIR Abs, defined as a titre $>16.8 \%$ (3 SDs above the mean for 70 healthy controls). A significantly higher MIR Ab titre $(p<0.001)$ was shown in generalised type $(47.9 \pm 19.2 \%)$ rather than in ocular type MG patients (16.4 $18.4 \%$ ). Bivariate regression analysis using both titre levels of MIR Ab and routine AChR binding $A b$ as variables revealed MIR Abs to be an exclusive indicator positively associated with disease severity (Myasthenia Gravis Foundation of America classification, $p<0.0001$; Quantitative MG score, $p=0.008$ ), the presence of bulbar symptoms $(p<0.0001)$ and thymoma $(p=0.016)$, and negatively associated with ocular MG $(p<0.0001)$.

Conclusions MIR Ab titre levels show much better correlations with factors related to disease severity compared with AChR binding Ab titres. The MIR Ab assay may be useful for predicting MG symptom severity, especially for discriminating between ocular and generalised types of MG.

\section{INTRODUCTION}

Myasthenia gravis (MG) is caused by failure of neuromuscular transmission mediated by autoantibodies (Abs) against acetylcholine receptor (AChR) and muscle-specific receptor tyrosine kinase $(\mathrm{MuSK})^{1} / \mathrm{LDL}$ receptor-related protein 4 (Lrp4) complex. ${ }^{2} 3$ The latter is a complex of AChR associated transmembrane postsynaptic proteins involved in AChR aggregation. ${ }^{4}$ The seropositivity rates for routine $\mathrm{AChR}$ binding $\mathrm{Ab}$ and MuSK Ab/
Lrp4 $\mathrm{Ab}$ in $\mathrm{MG}$ are $80-85 \%$ and $5-10 \% /<0.1 \%$ for MG patients in Japan, respectively, ${ }^{5}$ AChR related Abs in MG can be classified into three types: binding, blocking and modulating. The most commonly utilised and clinically useful AChR antibody assay (anti-AChR binding assay) measures IgG binding to ${ }^{125} \mathrm{I}$ - $\boldsymbol{\alpha}$-bungarotoxin labelled AChR by a radioimmunoprecipitation assay. Although the AChR binding $\mathrm{Ab}$ assay is useful diagnostically, ${ }^{6}$ titres of these Abs do not correlate well with disease severity. ${ }^{7}$ There appears to be some correlations between disease severity and $\mathrm{AChR}$ binding $\mathrm{Ab}$ titre on serial examinations during the clinical course of intrapatient evaluation, but such correlations are variable, ${ }^{8} 9$ and thus binding $\mathrm{Ab}$ titre levels cannot predict the prognosis in individual patients. Antibodies blocking the binding site of $\alpha$-bungarotoxin to AChR (blocking Abs) are detected in $50 \%$ of MG patients but blocking $\mathrm{Ab}$ titres correlate less well with severity, even when compared with binding Ab titres. ${ }^{10-12}$ On the other hand, for MuSK Ab positive MG, a correlation between MuSK Ab titre levels and disease severity was found, ${ }^{13}$ and the pathogenic relevance of the Abs has recently been confirmed clinically $^{1415}$ and experimentally. ${ }^{16} 17$

The main immunogenic region (MIR) of the $\mathrm{AChR}$, the principal target region of Abs, was originally defined by methods using the ability of a single rat monoclonal $\mathrm{Ab}$ to inhibit binding of various $\mathrm{AChR}$ Abs from MG patients. ${ }^{18}$ Monoclonal antibody 35 ( $\mathrm{mAb} 35)$ is a classic example of a $\mathrm{mAb}$ used for detecting MIR due to its high ability to bind to the MIR, and can passively transfer experimental autoimmune MG (EAMG) in an animal model. ${ }^{19}$ The MIR targeted by mAb 35 has been shown to be located at the extracellular end of each of the two $\alpha$ subunits of the pentameric $\mathrm{AChR}$ and has been confirmed by electron microscopy. ${ }^{20}$ More importantly, half or more of AChR Abs in MG patients bind to this region. ${ }^{21}$ Recently, MIR was shown to be a conformation dependent functional region at the extracellular end of each $\alpha$ subunit sequence, residues $1-81 .{ }^{22}{ }^{23}$ Considering the potential of Abs against MIR (MIR Abs) as causative agents in $\mathrm{MG}$, monitoring of these antibodies is probably useful in the clinical setting. However, the MIR Ab assay has not yet been applied clinically. Therefore, we developed 
a modified method for the mAb 35 competition $\mathrm{Ab}$ assay ${ }^{23}$ to detect autoantibodies against MIR (the MIR Ab assay), and investigated its clinical relevance in patients with MG.

\section{METHODS}

\section{Patients}

In this retrospective cohort study, we screened established MG patients seen at two neurological centres: Nagasaki University Hospital, from June 2008 until May 2009, and Hanamaki General Hospital, from May until August 2009, by reviewing the records of both clinical data and stored serum samples. To avoid potential bias, we enrolled consecutive patients over relatively short durations. The requirements for inclusion were as follows: frozen serum samples obtained before any treatment; complete medical records, with the Myasthenia Gravis Foundation of America (MGFA) clinical classifications at the worst conditions; continuing follow-up until study entry; and, for Hanamaki General Hospital, complete medical records with MGFA Quantitative MG score (OMG score) at serum sampling before treatment. Finally, 102 cases (Nagasaki University Hospital, $\mathrm{n}=72$; Hanamaki General Hospital, $\mathrm{n}=30$ ) met the criteria and were subjected to examinations (table 1). Recruitment of subjects at Hanamaki General Hospital was planned to analyse correlations between $\mathrm{QMG}$ score and serological data, excluding the influence of treatment, and to obtain clinical data blind to serological data measured at Nagasaki University. OMG score was determined by two participating neurologists (YN or KU). $\mathrm{KU}$ and $\mathrm{YN}$ are neurology specialists at Society Neurologica Japonica, and are experts in MG. At Nagasaki University Hospital, some subjects were not evaluated for OMG score before treatment and clinical data could not be analysed blind to the serological data. The worst condition for each patient was classified according to the MGFA classification and their clinical state at study entry following treatment was categorised according to MGFA post-intervention status.

The diagnosis of MG was based on clinical findings (fluctuating symptoms with easy fatigability and recovery after rest), with reduction in symptoms after intravenous administration of anticholinesterase, decremental muscle response to a train of

Table 1 Clinical characteristics of 102 myasthenia gravis patients

\begin{tabular}{ll}
\hline Characteristic & \\
\hline Age (years) (mean (SD)) & $58.6(17.1)$ \\
Male: female & $31: 71$ \\
Age at onset (years) (mean (SD)) & $45.2(20.5)$ \\
Time since onset (years) (mean (SD)) & $13.4(13.1)$ \\
EOMG & 43 \\
LOMG & 36 \\
Thymoma & 23 \\
Ocular MG & 23 \\
Bulbar symptoms & 45 \\
MGFA classification (I/II/II/IVN) & $23 / 55 / 11 / 4 / 9$ \\
Current dose of PSL (mg/day) (mean (SD)) & $6.4(5.7)$ \\
MGFA post-intervention status & \\
CSR & 3 \\
PR or better & 30 \\
MM-1 or better & 40 \\
MM-3 or better & 67 \\
\hline
\end{tabular}

CSR, complete stable remission; EOMG, early onset myasthenia gravis; LOMG, late onset myasthenia gravis; MG, myasthenia gravis; MGFA, Myasthenia Gravis Foundation of America; MM; minimal manifestations, PR; pharmacological remission:

PSL, prednisolone. low frequency repetitive nerve stimuli and the presence of AChR binding Abs. The follow-up lasted 2-25 years, but there was no correlation between stored durations of serum samples and binding $\mathrm{Ab}$ titres (data not shown). Among 102 patients enrolled, 23 were diagnosed as having the ocular type, reconfirmation 2 years after the onset of disease.

Sera from 70 healthy controls, from disease controls including 24 MG patients with MuSK Abs and 24 Lambert-Eaton myasthenic syndrome patients with $\mathrm{P} / \mathrm{O}$ type calcium channel Abs before treatment were obtained and studied at Nagasaki University Hospital.

All clinical information and blood samples were obtained after providing informed consent, and the study protocols were approved by the ethics committees from each institution.

\section{AChR binding Ab assay}

All steps were performed at $4^{\circ} \mathrm{C}$. Serum AChR binding Ab titre levels were measured by radioimmunoassay with ${ }^{125} \mathrm{I}$ $\alpha$-bungarotoxin using an AChR Ab kit II (Cosmic Co, Tokyo, Japan). First, $5 \mu \mathrm{l}$ of serum were incubated with an AChR extract labelled with $50000 \mathrm{cpm}$ of ${ }^{125} \mathrm{I}$ - $\alpha$-bungarotoxin overnight. Excess goat antihuman immunoglobulin (IgG) serum was then added to precipitate serum antibodies. Each sample was centrifuged at $3000 \mathrm{rpm}$ for $5 \mathrm{~min}$ and the pellets were washed three times with $20 \mathrm{mM}$ phosphate buffer $(\mathrm{pH} 7.4,0.01 \%$ TritonX-100) before counting. The radioactivity of the pellets was measured using a gamma counter (Auto Well Gamma System ARC-600; Aloca, Tokyo, Japan; 80\% counting efficiency). Positive serum samples with more than $10000 \mathrm{cpm}$ precipitated were titrated at different dilutions (from 20 to 200) and reassayed. AChR binding Ab titre levels were expressed as ${ }^{125} \mathrm{I}-\boldsymbol{\alpha}-$ bungarotoxin nanomoles precipitated per litre of serum with positive levels $\geq 0.5 \mathrm{nmol} / \mathrm{l}$ (3 SD above the mean for healthy controls $(n=70))$

\section{Monoclonal antibody}

Monoclonal antibody 35 (mAb 35) (lot No 023K4703) was purchased from Sigma-Aldrich Inc (St Louis, Missouri, USA). Initially, we confirmed the in vivo effects of $\mathrm{mAb} 35$ in animal experiments. mAb $35(150-300 \mu \mathrm{g})$ was injected intravenously into 4-week-old female Lewis rats. ${ }^{24}$ Rats were examined for weight loss, muscular weakness and fatigability. Tetraplegia began to appear at $12 \mathrm{~h}$, then severe weakness progressed and led to death 24-30 h after injection. Immunohistochemical studies for specimens from a motor point biopsy proved loss of AChR and deposition of complement at neuromuscular junctions. ${ }^{19}$ Using the same lot of $\mathrm{mAb} 35$, we developed the MIR Ab assay.

\section{MIR Ab assay: assay using mAb 35 competing with autoantibodies against MIR}

All steps were performed at $4^{\circ} \mathrm{C}$. After optimising the assay conditions, $5 \mu \mathrm{l}$ of patient serum were incubated with $50000 \mathrm{cpm}$ of ${ }^{125} \mathrm{I}-\boldsymbol{\alpha}$-bungarotoxin labelled AChR overnight, to which $1 \mu \mathrm{g} /$ tube $\left(6.67 \times 10^{-6} \mathrm{~mol} / \mathrm{l}\right)$ of $\mathrm{mAb} 35$ was added to compete for MIR with AChR Abs for $6 \mathrm{~h}$. The immune complexes of ${ }^{125} \mathrm{I}-\boldsymbol{\alpha}$-bungarotoxin labelled AChR with $\mathrm{AChR}$ $\mathrm{Abs}$ and/or $\mathrm{mAb} 35$ were precipitated using rabbit anti-rat IgG serum (Immuno Probe Co, Saitama, Japan), depleted with normal human sera. The precipitates were centrifuged and washed three times in $1 \mathrm{ml}$ of phosphate buffer and assayed using a gamma counter. Only mAb 35 without patient serum was incubated with and measured as a zero inhibition datum. The MIR Ab titre (ie, the inhibition rate by patient serum against $\mathrm{AChR}$ mAb 35 binding (\%)) was calculated as follows: 
(1-(cpm of MG patient serum and $\mathrm{mAb} 35) /(\mathrm{cpm}$ of only $\mathrm{mAb}$ 35) $) \times 100$. Three SDs above the mean for healthy controls $(n=70)$ was regarded as positive. The reliability of these precipitation methods was repeatedly confirmed.

\section{Statistics}

Differences between the two groups of patients were evaluated using the Student t test for continuous variables. Correlations were evaluated using Pearson's correlation for continuous variables or Spearman's rank correlation for categorical variables converted to numerical variables. Bivariate regression analysis using both AChR binding and MIR Abs as variables was performed to determine which was superior to the other for their relationship with clinical factors in MG patients. Values of $p<0.05$ were considered statistically significant. All continuous data are expressed as mean \pm SD. Statistical analyses were performed using Unistat V.5.6 statistical software (Unistat, London, UK).

\section{RESULTS}

We had first attempted to detect MIR Ab titre (\%) according to the original methods of Tzartos et al. ${ }^{23}$ Their methods determine the titre as the magnitude of inhibition by $\mathrm{mAb} 35$ of AChR-AChR Ab binding (1-(cpm of MG patient serum and $\mathrm{mAb} 35) /($ cpm of $M G$ patient serum) $) \times 100$, with the precipitation step using antihuman IgG serum incubated with normal rat sera, but their methods were not effective. AChR-mAb 35 complex was partly precipitated by antihuman IgG serum because reactivities against rat IgG in antihuman IgG serum could not be completely eliminated by preincubation with normal rat sera. However, when using antirat $\operatorname{IgG}$ serum incubated with normal human serum instead of antihuman IgG serum incubated with normal rat sera, the MIR Ab titre (\%) was successfully determined in a modified way as the inhibition rate by patient serum of AChR mAb 35 binding (1-(cpm of $\mathrm{MG}$ patient serum and $\mathrm{mAb} 35) /(\mathrm{cpm}$ of only $\mathrm{mAb} 35)) \times 100$. After further optimising the concentration of $\mathrm{mAb} 35$ and incubation time, we established the modified competitionimmunoprecipitation assay using mAb 35 and stably estimated MIR Ab titre levels.

MIR Ab titre levels ranged from $0 \%$ to $94.1 \%$. Eleven of 23 ocular type and 66 of 72 generalised type patients were positive for the presence of MIR Abs, defined as a titre $>16.8 \%$ (3 SDs above the mean for healthy controls $(4.8 \pm 4.0 \%))$. All disease controls with MuSK Ab positive MG $(7.2 \pm 7.2 \%, \mathrm{n}=24)$ or $\mathrm{P} / \mathrm{O}$ type calcium channel $\mathrm{Ab}$ positive Lambert-Eaton myasthenic syndrome $(7.5 \pm 5.0 \%, \mathrm{n}=24)$, were negative. The mean $\pm \mathrm{SD}$ of MIR Ab titre (\%) in ocular and generalised MG types were $16.4 \pm 8.4 \%$ and $47.9 \pm 19.2 \%$, respectively (figure $1 \mathrm{~A}$ ). There was thus a significant difference in MIR Ab titre levels between ocular and generalised MG patients $(p<0.001$, figure $1 \mathrm{~A})$. Furthermore, MIR Ab titre levels correlated with OMG score but AChR binding Ab titre levels did not (30 patients in a neurological centre) (tables 2 and 3). Notably, there were no ocular patients with MIR Ab titres $>40 \%$. AChR binding Ab titre levels
Figure 1 (A) Main immunogenic region antibody (MIR Ab) titre levels in healthy controls $(n=70)$, in Lambert-Eaton myasthenic syndrome (LEMS) patients $(n=24)$, in muscle specific receptor tyrosine kinase (MuSK) positive myasthenia gravis (MG) patients $(n=24)$ and in $M G$ patients $(n=102)$ as a function of Myasthenia Gravis Foundation of America (MGFA) classification. MIR Ab titre of $16.8 \%$ (mean+3SD) in 70 healthy controls, broken line or greater was considered to be positive. All disease controls were negative. There was a significant difference in MIR Ab titres between ocular and generalised MG patients $(\mathrm{p}<0.0001)$. The maximum MIR Ab titre of ocular MG was $38.1 \%$. AChR, acetylcholine receptor. (B) Routine AChR binding $A b$ titre levels in MG patients as a function of MGFA classification. Binding $A b$ titres were overlapped in ocular and generalised patients.
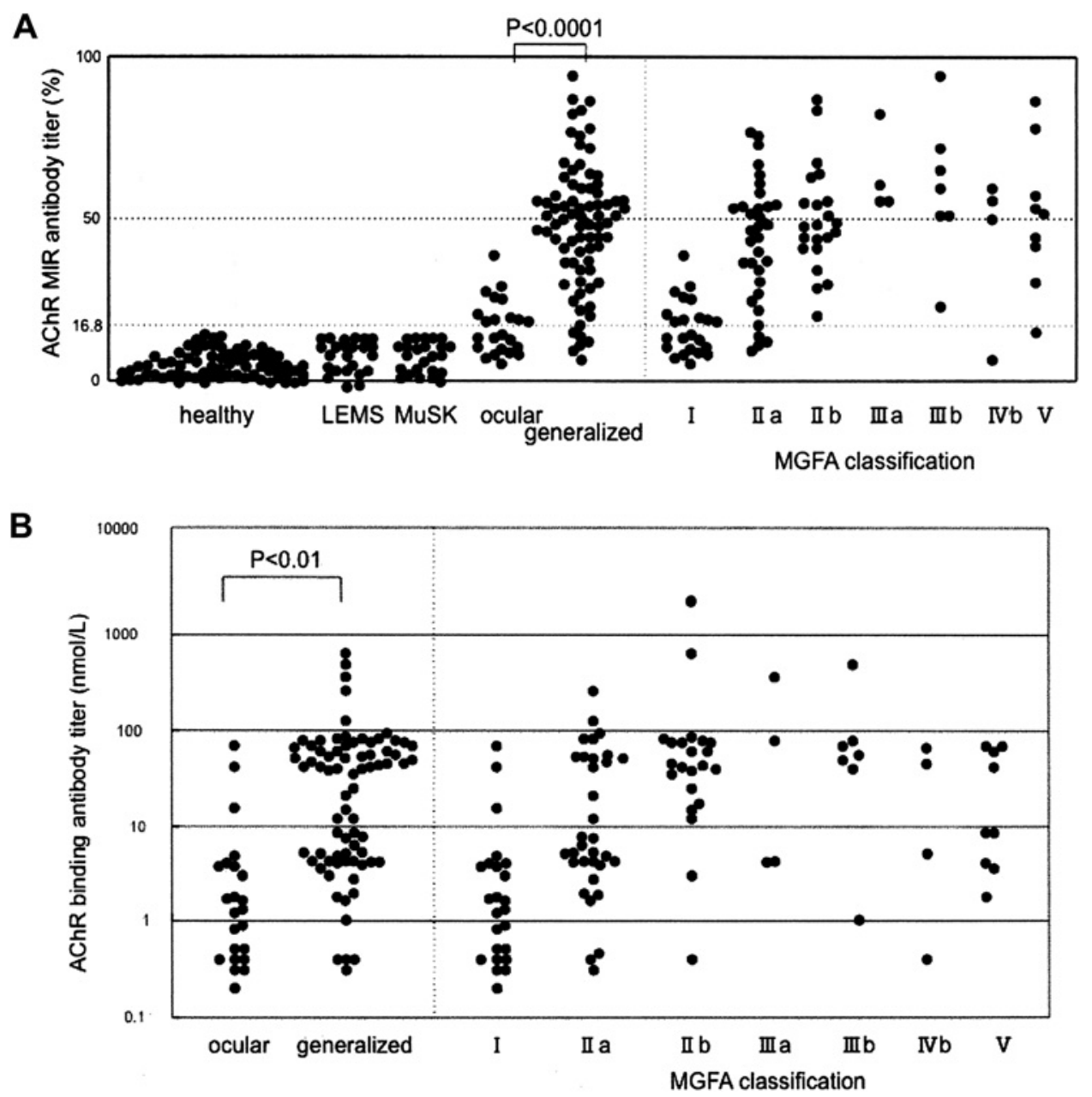
Table 2 Correlations of clinical factors with main immunogenic region and binding antibody before treatment (only $\mathrm{p}$ values are shown for binding antibody)

\begin{tabular}{|c|c|c|c|}
\hline \multirow[b]{2}{*}{ Clinical factors } & \multicolumn{2}{|l|}{ MIR Ab titre levels } & \multirow{2}{*}{$\begin{array}{l}\text { Binding Ab titre levels } \\
\text { p Value }\end{array}$} \\
\hline & Correlation (95\% CI) & p Value & \\
\hline Age (years) & $-0.17(-0.36$ to 0.03$)$ & $0.045^{*}$ & 0.28 \\
\hline Female sex\# & $0.23(0.04$ to 0.41$)$ & $0.009^{*}$ & 0.11 \\
\hline Age at onset (years) & $-0.05(-0.25$ to 0.15$)$ & 0.31 & 0.25 \\
\hline Time since onset (years) & $-0.15(-0.34$ to 0.05$)$ & 0.07 & 0.31 \\
\hline EOMG\# & $-0.01(-0.21$ to 0.19$)$ & 0.46 & 0.28 \\
\hline LOMG\# & $-0.17(-0.35$ to 0.03$)$ & $0.047^{*}$ & $0.035^{*}$ \\
\hline Thymoma\# & $0.21(0.02$ to 0.39$)$ & $0.015^{*}$ & $0.002^{*}$ \\
\hline Ocular MG\# & $-0.61(-0.72$ to -0.48$)$ & $<0.0001^{*}$ & $<0.0001^{*}$ \\
\hline Bulbar Symptoms\# & $0.44(0.27$ to 0.59$)$ & $<0.0001^{*}$ & $<0.0001^{*}$ \\
\hline QMG score $(n=30) \# \#$ & $0.54(0.22$ to 0.75$)$ & $0.001^{*}$ & 0.07 \\
\hline MGFA classification\# (at most acute presentation) & $0.57(0.43$ to 0.69$)$ & $<0.0001^{*}$ & $<0.0001^{*}$ \\
\hline Crisis\# & $0.12(-0.07$ to 0.31$)$ & 0.10 & 0.34 \\
\hline \multicolumn{4}{|l|}{ Post-intervention status } \\
\hline CSR\# & $-0.13(-0.33$ to 0.08$)$ & 0.10 & 0.14 \\
\hline PR or better\# & $-0.06(-0.27$ to 0.15$)$ & 0.28 & 0.15 \\
\hline MM-3 or better\# & $-0.16(-0.36$ to 0.05$)$ & 0.06 & 0.06 \\
\hline
\end{tabular}

\#Spearman's rank correlation.

\#\#The number of patients having the data of $\mathrm{QMG}$ score is only 30 from a single study site.

*Statistically significant $(p<0.05)$.

Pearson's correlation or ${ }^{\#}$ Spearman's rank correlation, $\mathrm{n}=102$

$\mathrm{Ab}$, antibody; CSR, complete stable remission; EOMG, early onset myasthenia gravis; LOMG, late onset myasthenia gravis; MG, myasthenia gravis; MGFA, Myasthenia Gravis Foundation of America; MIR, main immunogenic region; MM, minimal manifestations; PR; pharmacological remission; QMG score, quantitative MG score.

were also different between ocular and generalised $M G$ patients $(\mathrm{p}<0.01)$, but with considerable overlap between the two groups (figure 1B). There was a mild correlation between MIR Ab and AChR binding $\mathrm{Ab}$ titres (correlation coefficient $=0.43, \mathrm{n}=102$ ) (figure 2). The levels of MIR Abs in patients who experienced myasthenic crisis $(n=8)$ are shown as an open circle in figure 2, which shows similar levels $(50.3 \pm 22.1 \%)$ to those in other

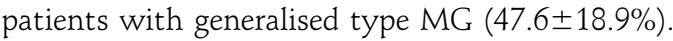

\section{Correlations of clinical factors with MIR Ab}

Positive correlations with MIR Ab titre levels before treatment were found for females, the presence of thymoma, the presence of bulbar symptoms, OMG score (blinded data, $n=30$ ) and
MGFA classification at the worst condition for each patient (table 2). Negative correlations were found for age, late onset MG ( $\geq 50$ years) with no thymoma and ocular type MG (table 2). Correlations of age, female sex and OMG score with binding $\mathrm{Ab}$ titre levels were not significant but those of other clinical factors with binding Ab (only $\mathrm{p}$ values are shown in table 2) showed similar results to MIR Ab. The univariate correlation analysis could not clarify the superiority of MIR or AChR binding Abs for their effects on clinical factors.

Bivariate (MIR and binding $\mathbf{A b}$ ) regression to clinical factors We further performed bivariate regression analysis using both MIR and AChR binding $\mathrm{Ab}$ titre levels before treatment as

Table 3 Bivariate (main immunogenic region and binding antibody before treatment) regression analysis of clinical factors

\begin{tabular}{|c|c|c|c|c|c|}
\hline \multirow[b]{2}{*}{ Clinical factors } & \multirow[b]{2}{*}{ R Value } & \multicolumn{2}{|l|}{ AChR MIR Ab } & \multicolumn{2}{|l|}{ AChR binding Ab } \\
\hline & & Coefficient (95\% CI) & p Value & Coefficient (95\% CI) & $\overline{\text { p Value }}$ \\
\hline Age (years) & -0.16 & $-0.13(-0.30$ to 0.04$)$ & 0.14 & $0.00(-0.04$ to 0.04$)$ & 0.91 \\
\hline Female sex & 0.20 & $0.005(0.000$ to 0.009$)$ & $0.048 *$ & $-0.000(-0.001$ to 0.001$)$ & 0.52 \\
\hline Age at onset (years) & -0.08 & $-0.01(-0.22$ to 0.20$)$ & 0.91 & $-0.02(-0.07$ to 0.03$)$ & 0.50 \\
\hline Time since onset (years) & -0.19 & $-0.12(-0.25$ to 0.02$)$ & 0.08 & $0.02(-0.01$ to 0.05$)$ & 0.23 \\
\hline EOMG & 0.11 & $-0.001(-0.006$ to 0.004$)$ & 0.64 & $0.001(-0.001$ to 0.002$)$ & 0.30 \\
\hline LOMG & -0.21 & $-0.004(-0.009$ to -0.001$)$ & 0.11 & $-0.000(-0.002$ to 0.001$)$ & 0.57 \\
\hline Thymoma & 0.25 & $0.005(0.001$ to 0.009$)$ & $0.016^{*}$ & $-0.001(-0.001$ to 0.001$)$ & 0.59 \\
\hline Ocular MG & -0.62 & $-0.012(-0.016$ to -0.009$)$ & $<0.0001^{*}$ & $-0.000(-0.001$ to 0.001$)$ & 0.64 \\
\hline Bulbar symptoms & 0.45 & $0.010(0.006$ to 0.015$)$ & $<0.0001^{*}$ & $0.000(-0.001$ to 0.001$)$ & 0.98 \\
\hline OMG score $(n=30)$ & 0.54 & $0.162(0.046$ to 0.278$)$ & $0.008^{*}$ & $-0.002(0.030$ to 0.025$)$ & 0.86 \\
\hline MGFA classification (at worst condition) & 0.44 & $0.024(0.014$ to 0.035$)$ & $<0.0001^{*}$ & $-0.001(-0.004$ to 0.002$)$ & 0.40 \\
\hline Crisis & 0.18 & $0.003(0.000$ to 0.006$)$ & 0.08 & $-0.000(-0.001$ to 0.000$)$ & 0.23 \\
\hline \multicolumn{6}{|l|}{ Post-intervention status } \\
\hline CSR & -0.13 & $-0.001(-0.003$ to 0.001$)$ & 0.29 & $-0.000(-0.001$ to 0.001$)$ & 0.99 \\
\hline PR or better & -0.09 & $-0.001(-0.007$ to 0.004$)$ & 0.66 & $-0.000(-0.002$ to 0.001$)$ & 0.70 \\
\hline MM-3 or better & -0.22 & $-0.004(-0.009$ to 0.001$)$ & 0.08 & $-0.000(-0.001$ to 0.001$)$ & 0.89 \\
\hline
\end{tabular}

*Statistically significant $(p<0.05)$.

$\mathrm{n}=102$.

$\mathrm{Ab}$, antibody; AChR, acetylcholine receptor; CSR, complete stable remission; EOMG, early onset myasthenia gravis; LOMG, late onset myasthenia gravis; MG, myasthenia gravis; MGFA,

Myasthenia Gravis Foundation of America; MIR, main immunogenic region; MM, minimal manifestations; PR; pharmacological remission; QMG score, quantitative MG score. 


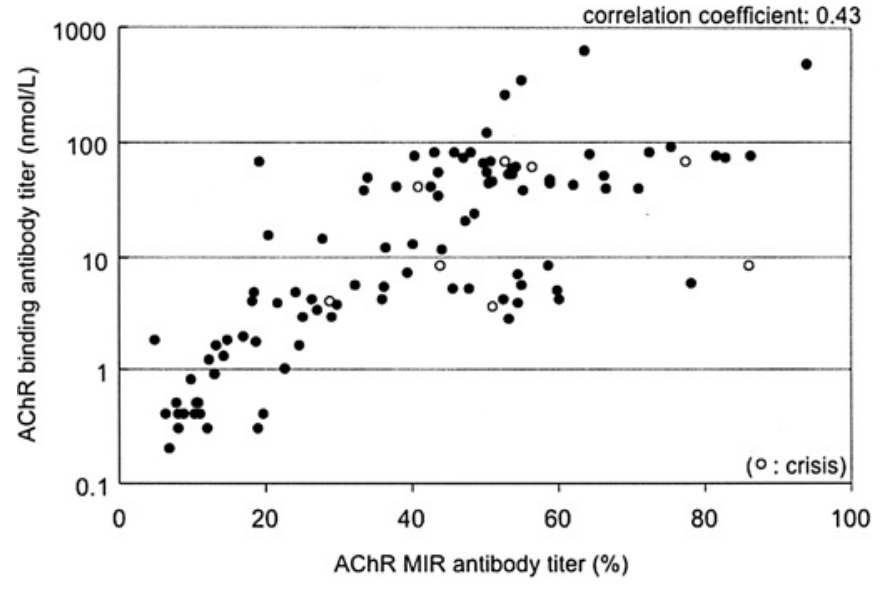

Figure 2 Correlation between main immunogenic region (MIR) and acetylcholine receptor (AChR) binding antibody titre levels $(n=102)$.

variables to determine which $\mathrm{Ab}$ type was superior regarding their effects on clinical factors. This analysis clearly demonstrated that MIR Ab titre was an exclusive indicator positively associated with female sex $(p=0.048)$, disease severity (QMG score and MGFA classification) $(p=0.008, p<0.0001)$, the presence of bulbar symptoms $(p<0.0001)$ and thymoma $(p=0.016)$, and negatively associated with ocular MG $(\mathrm{p}<0.0001)$ (table 3).

Even if analysing only 30 patient datasets blind to the serological data, the superiority of MIR over AChR binding Abs in terms of a positive association with the presence of bulbar symptoms $(p=0.01$ vs $p=0.96)$ and negative association with ocular MG ( $p=0.0001$ vs $p=0.15$ ) remained obvious, although associations with other clinical factors did not reach significance due to the small sample size.

\section{DISCUSSION}

We developed a modified MIR Ab assay and clearly demonstrated that MIR Ab titre levels exhibit much better correlations with factors related to the severity of MG compared with AChR binding $\mathrm{Ab}$ titres. The original MIR Ab assay was reported by Tzartos et al. ${ }^{23}$ They reported that any particular associations between MIR Ab levels and disease severity could not be found. Although there have been later reports of MIR Ab assays, ${ }^{25} 26$ such assays using mAbs have not yet been applied clinically. In our study, however, a significantly higher level of MIR Ab titre levels was shown in generalised type rather than in ocular type MG patients, and notably, all ocular patients showed MIR Ab levels $<40 \%$. Furthermore, bivariate regression analysis revealed that higher MIR Ab levels were exclusively indicative of severe disease, with generalised symptoms and lower MIR Ab levels limited to ocular symptoms. We also found a correlation between blinded QMG score and MIR Ab but not with AChR binding $\mathrm{Ab}$ titre levels. These results suggest that MIR Ab levels are probably promising indicators, useful for predicting disease severity and discriminating between ocular and generalised types, and may further suggest that MIR Abs are the principal causative agents which a play crucial role in the pathogenesis of MG.

It is unknown whether there exists only a single MIR on each $\alpha$ subunit of the AChR for pathogenic $\mathrm{Ab}$ binding in $\mathrm{MG}$. Tzartos et al showed that MIR was located at the extracellular end of the $\alpha$ subunit, including sequence residues $66-76$, and that at least half of AChR Abs in MG were directed at this MIR. ${ }^{21}$ On the other hand, Lennon et al reported the possibility of an AChR $\alpha$ subunit 125-147 near the ACh binding site as a potential target for pathogenic Abs in MG patients, ${ }^{25}$ but which has yet to be confirmed. In 1995, Beroukhim and Unwin reported decisive evidence supporting the localisation of MIR at the extracellular end of $\alpha$ subunits using electron microscopy. ${ }^{20}$ They analysed them three-dimensionally and demonstrated that MIR bound with mAb 35 was localised at the extreme synaptic end of each $\alpha$ subunit. As this region is far from the ACh binding site $^{27}$ MIR Abs do not competitively inhibit AChR function. ${ }^{28}$ Recently, Luo et al demonstrated three-dimensional proximity in localisation between the $\mathrm{N}$ terminal $\alpha$ helix residues $1-14$ and the loop residues $60-81$, which suggests the conformational dependence of the antigenic structure of MIR. ${ }^{29}$ Considering these results above, our MIR Ab assay probably detects Abs against the antigenic conformational structure of the extreme synaptic end of each $\alpha$ subunit, which crosslink to the two adjacent AChRs.

Although $\mathrm{MG}$ is often commented on as the best understood autoimmune disorder, the pathogenesis of ocular MG remains enigmatic. $^{30}$ As stated previously, at the onset of disease, approximately $50 \%$ of MG patients present with purely ocular symptoms. $^{31} 32$ Of these patients, $50-60 \%$ finally develop generalised myasthenia; such disease courses occur within 2 years after onset in the majority of cases. ${ }^{31} 32$ A few studies have addressed the pathomechanisms of ocular myasthenia, analysing biopsied motor endplates ${ }^{33-35}$ and EAMG. ${ }^{36} 37$ Pathological changes in the ultrastructure of the motor endplates were observed in non-weak limb muscles of patients with ocular MG as well as in generalised MG. ${ }^{38}$ There was a decrease in AChR density at the motor endplates of the biceps muscle, ${ }^{34}$ and intercostal muscles, ${ }^{33}$ even in ocular MG, although a significant difference in $\mathrm{AChR}$ density levels in biceps branchii muscles was observed between ocular and generalised MG. ${ }^{35}$ These results suggest that the membrane destruction by complement mediated damage also occurs in ocular MG, the degree of which is weaker than that in generalised MG. Regarding the pathomechanisms of ocular myasthenia, the low titre levels of MIR Abs observed in our ocular MG patients raise two possibilities: (1) MIR Abs are actually directed against MIR in ocular MG but our assay is not sensitive enough to detect them and (2) most Abs in ocular MG are directed against unknown determinants other than the present MIR. Recently, Kaminsky's research group proposed the hypothesis that extraocular muscles could be particularly susceptible to complement mediated injury in both EAMG and MG patients. ${ }^{39}$ If the present MIR is principally pathogenic and Kaminski's complement hypothesis is correct, possibility (1) appears likely.

Although limitations exist in the retrospective and partially unblinded design, the data we have presented here suggest that the MIR Ab assay is probably useful for predicting MG severity, especially for discriminating between ocular and generalised MG. Our results further suggest that the MIR is the major target region of the $A C h R$ for autoantibody responses in human MG clinically. To confirm the clinical relevance of MIR Abs and the pathological significance of MIR in MG, multicentre, prospective, double blind studies are required.

Acknowledgements The authors thank Ms Yuko Ohyama and Ms Michiko Morita for technical assistance and the patients who participated in this study.

Contributors TM designed and conducted the antibody experiments, and wrote the paper. KU and YN diagnosed the patients, conducted the statistical processing and wrote the paper. RN, MT, TF and TY diagnosed the patients and conducted the antibody experiments. MT and AK conceived the study and designed the experiments MM conceived the study, designed the experiments and wrote the paper. 
Funding This work was supported in part by the Health and Labour Sciences Research Grant on Intractable Diseases (Neuroimmunological Diseases) from the Ministry of Health, Labour and Welfare, Japan.

\section{Competing interests None.}

Ethics approval The ethics committees from Nagasaki University and Hanamaki General Hospital approved the study.

Provenance and peer review Not commissioned; externally peer reviewed.

\section{REFERENCES}

1. Hoch W, McConville J, Helms S, et al. Auto-antibodies to the receptor tyrosine kinase MuSK in patients with myasthenia gravis without acetylcholine receptor antibodies. Nat Med 2001;7:365-8.

2. Higuchi $\mathbf{0}$, Hamuro $\mathrm{J}$, Motomura $\mathrm{M}$, et al. Autoantibodies to LDL receptor-related protein 4 in myasthenia gravis. Ann Neurol 2011;69:418-22.

3. Zhang B, Tzartos JS, Belimezi M, et al. Autoantibodies to lipoprotein-related protein 4 in patients with double-seronegative myasthenia gravis. Arch Neurol 2012; 69:445-51

4. Wu H, Xiong WC, Mei L. To build a synapse: signaling pathways in neuromuscular junction assembly. Development 2010:137:1017-33.

5. Motomura M. The pathophysiology and treatment of autoimmune neuromuscular junction diseases. Rinsho Shinkeigaku 2011:51:872-6.

6. Vincent A, Newsom-Davis J. Acetylcholine receptor antibody as a diagnostic test for myasthenia gravis: results in 153 validated cases and 2967 diagnostic assays. $J$ Neurol Neurosurg Psychiatry 1985;48:1246-52.

7. Somnier FE. Clinical implementation of anti-acetylcholine receptor antibodies. Neurol Neurosurg Psychiatry 1993;56:496-504.

8. Tindall RS. Humoral immunity in myasthenia gravis: biochemical characterization of acquired antireceptor antibodies and clinical correlations. Ann Neurol 1981;10:437-47.

9. Vincent A, Newsom Davis J. Anti-acetylcholine receptor antibodies. J Neurol Neurosurg Psychiatry 1980;43:590-600.

10. Besinger UA, Toyka KV, Hömberg M, et al. Myasthenia gravis: long-term correlation of binding and bungarotoxin blocking antibodies against acetylcholine receptors with changes in disease severity. Neurology 1983;33:1316-21.

11. Howard FM Jr, Lennon VA, Finley J, et al. Clinical correlations of antibodies that bind, block, or modulate human acetylcholine receptors in myasthenia gravis. Ann N Y Acad Sci 1987;505:526-38

12. Pachner AR. Anti-acetylcholine receptor antibodies block bungarotoxin binding to native human acetylcholine receptor on the surface of TE671 cells. Neurology 1989;39:1057-61.

13. Bartoccioni E, Scuderi F, Minicuci GM, et al. Anti-MuSK antibodies: correlation with myasthenia gravis severity. Neurology 2006;67:505-7.

14. Sanders DB, El-Salem K, Massey JM, et al. Clinical aspects of MuSK antibody positive seronegative MG. Neurology 2003;60:1978-80.

15. Guptill JT, Sanders DB, Evoli A. Anti-MuSK antibody myasthenia gravis: clinical findings and response to treatment in two large cohorts. Muscle Nerve 2011:44:36-40.

16. Shigemoto K, Kubo S, Maruyama N, et al. Induction of myasthenia by immunization against muscle-specific kinase. J Clin Invest 2006:116:1016-24.

17. Punga AR, Lin S, Oliveri F, et al. Muscle-selective synaptic disassembly and reorganization in MuSK antibody positive MG mice. Exp Neurol 2011: 230:207-17.
18. Tzartos SJ, Lindstrom JM. Monoclonal antibodies used to probe acetylcholine receptor structure: localization of the main immunogenic region and detection of similarities between subunits. Proc Natl Acad Sci U S A 1980;77:755-9.

19. Tzartos S, Hochschwender S, Vasquez $\mathrm{P}$, et al. Passive transfer of experimental autoimmune myasthenia gravis by monoclonal antibodies to the main immunogenic region of the acetylcholine receptor. J Neuroimmunol 1987:15:185-94.

20. Beroukhim R, Unwin N. Three-dimensional location of the main immunogenic region of the acetylcholine receptor. Neuron 1995;15:323-31.

21. Tzartos SJ, Barkas T, Cung MT, et al. Anatomy of the antigenic structure of a large membrane autoantigen, the muscle-type nicotinic acetylcholine receptor. Immunol Rev 1998;163:89-120.

22. Luo J, Lindstrom J. Antigenic structure of the human muscle nicotinic acetylcholine receptor main immunogenic region. J Mol Neurosci 2010;40:217-20.

23. Tzartos SJ, Seybold ME, Lindstrom J. Specificity of antibodies to acetylcholine receptors in sera from myasthenia gravis patients measured by monoclonal antibodies. Proc Natl Acad Sci 1982;79:188-92.

24. Poulas K, Tsouloufis T, Tzartos SJ. Treatment of passively transferred experimenta autoimmune myasthenia gravis using papain. Clin Exp Immunol 2000;120:363-8.

25. Lennon VA, McCormick DJ, Lambert EH, et al. Region of peptide 125-147 of acetylcholine receptor alpha subunit is exposed at neuromuscular junction and induces experimental autoimmune myasthenia gravis, T-cell immunity, and modulating autoantibodies. Proc Natl Acad Sci U S A 1985;82:8805-9.

26. Heidenreich F, Vincent A, Willcox N, et al. Anti-acetylcholine receptor antibody specificities in serum and in thymic cell culture supernatants from myasthenia gravis patients. Neurology 1988;38:1784-8.

27. Brejc K, van Dijk WJ, Klaassen RV, et al. Crystal structure of an ACh-binding protein reveals the ligand-binding domain of nicotinic receptors. Nature 2001;411:269-76.

28. Lindstrom JM. Nicotinic acetylcholine receptors of muscles and nerves: comparison of their structures, functional roles, and vulnerability to pathology. Ann N Y Acad Sci 2003;998:41-52

29. Luo J, Taylor $\mathrm{P}$, Losen $\mathrm{M}$, et al. Main immunogenic region structure promotes binding of conformation-dependent myasthenia gravis autoantibodies, nicotinic acetylcholine receptor conformation maturation, and agonist sensitivity. J Neurosci 2009:29:13898-908.

30. Kusner LL, Puwanant A, Kaminski HJ. Ocular myasthenia: diagnosis, treatment, and pathogenesis. Neurologist 2006;12:231-9.

31. Bever CT Jr, Aquino AV, Penn AS, et al. Prognosis of ocular myasthenia. Ann Neurol 1983;14:516-19.

32. Oosterhuis HJ. The natural course of myasthenia gravis: a long term follow up study. J Neurol Neurosurg Psychiatry 1989;52:1121-7.

33. Lecky BR, Morgan-Hughes JA, Landon DN, et al. Intercostal muscle acetylcholine receptors in longstanding ocular myasthenia. Lancet 1980;2:1311-12.

34. Tsujihata M, Yoshimura T, Satoh A, et al. Diagnostic significance of IgG, C3, and C9 at the limb muscle motor end-plate in minimal myasthenia gravis. Neurology 1989:39:1359-63.

35. Shiraisi H, Motomura M, Yoshimura T, et al. Acetylcholine receptor loss and postsynaptic damage in MuSK antibody-positive myasthenia gravis. Ann Neurol 2005; 57:289-93

36. Oda K. Differences in acetylcholine receptor-antibody interactions between extraocular and extremity muscle fibers. Ann N Y Acad Sci 1993:681:238-55.

37. Kaminski HJ, Li Z, Richmonds C, et al. Complement regulators in extraocular muscle and experimental autoimmune myasthenia gravis. Exp Neurol 2004;189:333-42.

38. Tsujihata M, Hazama $\mathrm{R}$, Ishii $\mathrm{N}$, et al. Limb muscle endplates in ocular myasthenia gravis: quantitative ultrastructural study. Neurology 1979;29:654-61.

39. Soltys J, Gong B, Kaminski HJ, et al. Extraocular muscle susceptibility to myasthenia gravis: unique immunological environment? Ann N Y Acad Sci 2008;1132:220-4. 
Antibodies against the main immunogenic region of the acetylcholine receptor correlate with disease severity in myasthenia gravis

Tomoko Masuda, Masakatsu Motomura, Kimiaki Utsugisawa, et al.

J Neurol Neurosurg Psychiatry 2012 83: 935-940 originally published online July 4,2012

doi: 10.1136/jnnp-2012-302705

Updated information and services can be found at:

http:/jnnn.bmj.com/content/83/9/935.full.html

These include:

References This article cites 39 articles, 16 of which can be accessed free at: http://jnnp.bmj.com/content/83/9/935.full.html\#ref-list-1

Email alerting Receive free email alerts when new articles cite this article. Sign up in service the box at the top right corner of the online article.

Topic Articles on similar topics can be found in the following collections

Collections

Immunology (including allergy) (1407 articles)

Neuromuscular disease (1004 articles)

Drugs: CNS (not psychiatric) (1396 articles)

Notes

To request permissions go to:

http://group.bmj.com/group/rights-licensing/permissions

To order reprints go to:

http://journals.bmj.com/cgi/reprintform

To subscribe to BMJ go to:

http://group.bmj.com/subscribe/ 